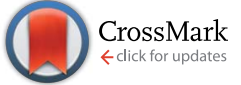
8047
Cite this: J. Mater. Chem. C, 2014, 2,

\section{Enhancement of photovoltaic performance by increasing conjugation of the acceptor unit in benzodithiophene and quinoxaline copolymers $\uparrow$}

\author{
Tong Hu,,$^{\mathrm{ab}}$ Liangliang Han,,$^{\mathrm{b}}$ Manjun Xiao, ${ }^{\mathrm{b}}$ Xichang Bao, ${ }^{\mathrm{b}}$ Ting Wang, \\ Mingliang Sun ${ }^{\star a}$ and Renqiang Yang*b
}

\begin{abstract}
Copolymers based on benzodithiophene and quinoxaline, represented by 4,8-bis(5-(3,4,5-tris(octyloxy)phenyl)thiophen-2-yl)benzo[1,2-b:4,5- $\left.b^{\prime}\right]$ dithiophene (TOBDT) and 2,3-diphenyl-5,8-di(thiophen-2-yl)quinoxaline (TQ1) or 10,13-bis(4-(2-ethylhexyl)thiophen-2-yl)dibenzo[a,c]phenazine (TQ2), were synthesized via a Stille coupling reaction. By increasing the conjugation in the TQ2 unit, the polymer based on TQ2 showed a narrower band gap $\left(E_{\mathrm{g}}\right)$, a lower highest occupied molecular orbital energy level and enhanced interchain $\pi-\pi$ interactions. Polymer solar cells based on TQ2 showed a simultaneous enhancement of the open-circuit voltage $\left(V_{o c}\right)$, short-circuit current density $\left(J_{s c}\right)$ and fill factor (FF) compared with polymer solar cells based on the TQ1 polymer. A good power conversion efficiency of $4.24 \%$ was achieved by solar cells based on the TQ2 polymer and $[6,6]$-phenyl- $C_{71}$-butyric acid methyl ester composite. These preliminary results indicate that increasing the acceptor unit (quinoxaline) conjugation is an effective way of improving the performance of polymer solar cells.
\end{abstract}

Received 4th July 2014

Accepted 31st July 2014

DOI: $10.1039 / c 4 t c 01440 \mathrm{e}$

www.rsc.org/MaterialsC

\section{Introduction}

Much progress has recently been made in the development of polymer solar cells (PSCs), which are considered to be promising sustainable solar energy converters as a result of their unique advantages of low cost, light weight and potential application in flexible devices with large surface areas. ${ }^{1-6}$ It is widely recognized that the bulk heterojunction structure, which is formed by blending an electron-rich conjugated polymer as the donor and an electron-deficient fullerene as the acceptor, is the most efficient configuration for PSCs. ${ }^{7}$ The best fullerene derivative currently available for use in PSCs is $[6,6]$-phenyl- $\mathrm{C}_{61^{-}}$ butyric acid methyl ester $\left(\mathrm{PC}_{61} \mathrm{BM}\right)$ or $\mathrm{PC}_{71} \mathrm{BM}^{\mathbf{1 , 2 , 4 , \mathbf { 8 }}}$ Most efforts have focused on engineering the molecular structure to tune the band gaps $\left(E_{\mathrm{g}}\right)$ and energy levels of the polymer donors. Highperformance PSCs require narrow band gaps and suitable energy levels to maximize the short-circuit current $\left(J_{\mathrm{sc}}\right)$, opencircuit voltage $\left(V_{\mathrm{oc}}\right)$ and high carrier mobility to facilitate hole transport. Poly(3-hexylthiophene) (P3HT) is one of the most

\footnotetext{
${ }^{a}$ Institute of Material Science and Engineering, Ocean University of China, Qingdao 266100, People's Republic of China. E-mail: mlsun@ouc.edu.cn; Fax: +86-53266781927; Tel: +86-532-66781690

${ }^{b}$ CAS Key Laboratory of Bio-based Materials, Qingdao Institute of Bioenergy and Bioprocess Technology, Chinese Academy of Sciences, Qingdao 266101, People's Republic of China. E-mail: yangrq@qibebt.ac.cn; Fax: +86-532-80662778; Tel: +86532-80662700

$\dagger$ Electronic supplementary information (ESI) available. See DOI: 10.1039/c4tc01440e

\$ These authors contributed equally to this work.
}

promising donor materials as a result of its easy synthesis, high hole mobility and good solubility. The power conversion efficiency (PCE) of PSCs based on P3HT can reach 7\%, with an external quantum efficiency (EQE) of about 70\%.,9-12 However, the large $E_{\mathrm{g}}$ value for P3HT and relatively high energy of the highest occupied molecular orbital (HOMO) (about $-5.0 \mathrm{eV}$ ) lead to narrow absorption spectra and a low value for $V_{\mathrm{oc}}$.

Alternating donor-acceptor (D-A) conjugated copolymers can be used to overcome these issues because the absorption and energy levels of the copolymers can be easily tuned by engineering the molecular structures. Using this method, many different D-A copolymers have been synthesized and these materials show excellent photovoltaic properties with PCEs as high as $8-9 \% .^{13,14}$ Of these, the benzo[1,2- $\left.b: 4,5-b^{\prime}\right]$ dithiophene (BDT) unit has been widely used as the donor unit in D-A copolymers and shows promising photovoltaic effects. ${ }^{\mathbf{1 5 - 2 0}}$ Further research has been directed towards designing polymers based on BDT and high PCE values have been achieved ${ }^{21-25}$ by copolymerizing BDT with 4,7-bis(thiophen-2-yl)benzo[ $[c][1,2,5]$ thiadiazole, ${ }^{26}$ thieno[3,4-c]pyrrole-4,6-dione, ${ }^{27}$ diketopyrrolopyrrole $^{28}$ and thieno[3,4- $\left.b\right]$-thiophene. ${ }^{29}$

In addition to these acceptors, electron-deficient quinoxaline-based units have also been studied and widely used as narrow $E_{\mathrm{g}}$ polymers for PSC applications $\mathrm{s}^{30-34}$ because quinoxaline can be easily modified at the 2 and 3 positions. The quinoxaline derivative 2,3-diphenyl-5,8-di(thiophen-2-yl)quinoxaline (TQ1), which has two separated phenyl rings, has the advantages of easy synthesis and versatility. However, most of the polymers based on TQ1 have a large $E_{\mathrm{g}}$ and low charge 
carrier mobility ${ }^{\mathbf{3 3}, 35}$ as a result of the less planar structure caused by the two separated phenyl rings. ${ }^{36}$

We report here a more planar dibenzo[a,c]phenazine that facilitates intermolecular packing and charge transport of the acceptor unit. In addition, the extended $\pi$-conjugation of the fused quinoxaline functions as a stronger electron acceptor. ${ }^{36} 3$ (2-Ethylhexyl)thiophene was attached to both sides of dibenzo $[a, c]$ phenazine to build a D-A-D structure with the purpose of obtaining a narrow $E_{\mathrm{g}}$. Using this method, 10,13-bis[4-(2-ethylhexyl)thiophen-2-yl $]$ dibenzo[a,c]phenazine (TQ2) was synthesized. TQ2 can be easily purified by column chromatography because of the improved solubility when two 2-ethylhexyl chains are introduced. Interestingly, when a side chain is introduced to the 4-position of thiophene, there is almost no influence on $E_{\mathrm{g}}$ and sometimes $V_{\text {oc }}$ is improved. 4,8-Bis(2-(3,4,5-tris(octyloxy)phenyl)thiophene-2-yl)benzo[1,2- $\left.b: 4,5-b^{\prime}\right]$ dithiophene (TOBDT) with six alkoxylated substituents has recently been designed by our group and this has improved the processing of the polymers due to its excellent solubility. ${ }^{37}$ Therefore the two polymers PTOBDTTQ1 and PTOBDTTQ2 were synthesized by copolymerizing TOBDT with TQ1 or TQ2, respectively.

\section{Results and discussion}

\section{Synthesis and characterization}

Scheme 1 shows the molecular structures of PTOBDTTQ1 and PTOBDTTQ2. Scheme 2 shows the detailed synthetic routes used to obtain the TQ1 and TQ2 monomers.

Considering the difficulty of purifying the target monomer TQ2, which consists of a more planar structure, 3-(2-ethylhexyl) thiophene was attached to both sides of monomer 2 via a Stille coupling reaction to increase the solubility of the TQ2 monomer. This may be beneficial for the molecular weight, which could affect the PCE of the device. The target monomers DBrTQ1 and DBrTQ2 were obtained after the bromination of the monomers TQ1 and TQ2, respectively, with $N$-bromosuccinimide (NBS) in chloroform/acetic acid solution. The Stille coupling polymerization between the monomer TOBDTSn and DBrTQ1 or DBrTQ2 with a tris(dibenzylideneacetone)dipalladium $\left[\mathrm{Pd}_{2}(\mathrm{dba})_{3} / \mathrm{P}(o \text {-tol })_{3}\right]$ catalyst in toluene gave the polymers PTOBDTTQ1 and PTOBDTTQ2. The final polymers were purified using Soxhlet extraction and silica gel column chromatography and showed good solubility in organic solvents such as tetrahydrofuran (THF), chloroform, chlorobenzene and
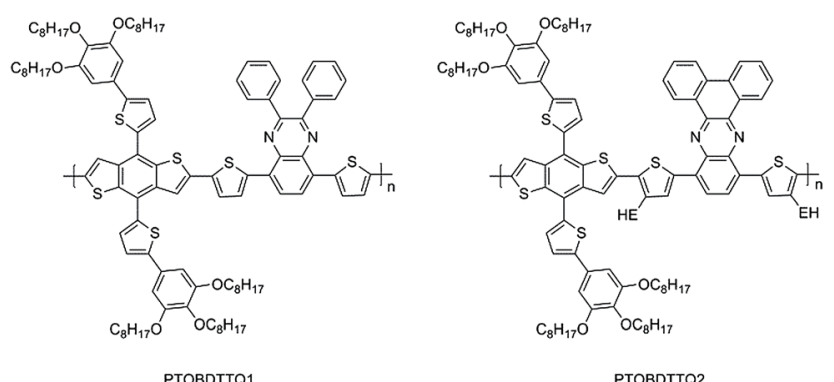

Scheme 1 Polymer structures of PTOBDTTQ1 and PTOBDTTQ2 (EH =2-ethylhexyl).

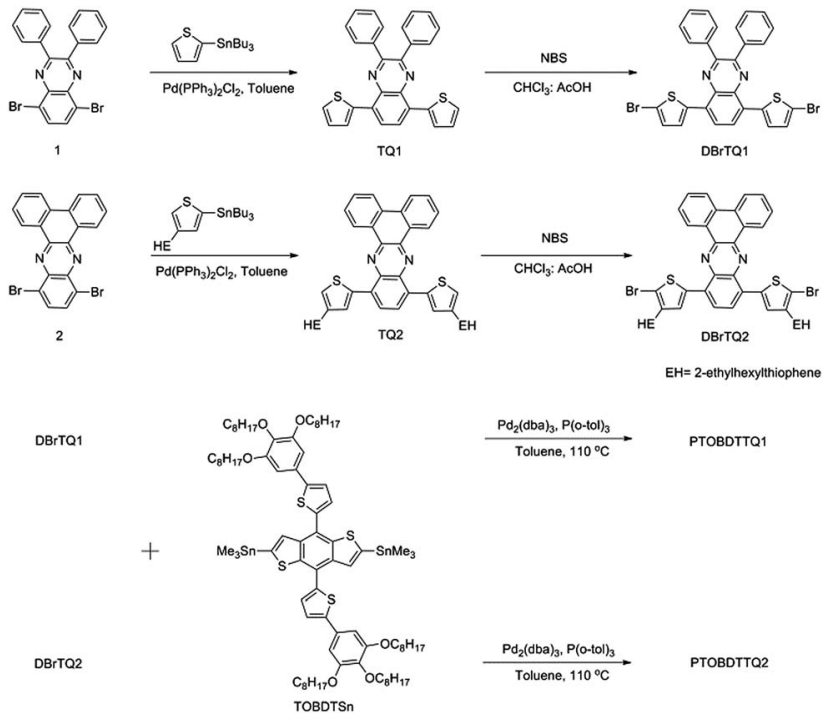

Scheme 2 Synthetic routes used to obtain the monomers and copolymers.

$o$-dichlorobenzene at room temperature. The molecular weight of the polymers and their polydispersity index (PDI) were measured by gel permeation chromatography (GPC) using monodispersed polystyrene as the standard and THF as the eluent (Table 1). The number average molecular weight $\left(M_{\mathrm{n}}\right)$ and PDI of both polymers are $20 \mathrm{kDa}, 1.08$ and $20 \mathrm{kDa}, 1.09$, respectively. This may prove that the introduction of 2-ethylhexyl as a side chain to the 4-position of thiophene is helpful when the monomer has solubility problems. The decomposition temperatures $\left(T_{\mathrm{d}}\right)$ of the polymers are 356 and $379{ }^{\circ} \mathrm{C}$, respectively, indicating sufficient thermal stability for application in PSCs.

\section{Optical properties}

Fig. 1 shows the UV-visible absorption spectra of the polymers in chloroform solution and in thin films. Both of the polymers showed two absorption peaks in chloroform solution, which is a common feature of D-A polymers and is caused by the strong intramolecular charge transfer (CT) state. The absorption peak red-shifted for both the polymers in their thin film forms. The absorption around the CT band became stronger and wider, which is ascribed to intermolecular CT between the molecular backbones. PTOBDTTQ2 has a lower energy absorption than PTOBDTTQ1 in both solution and as a thin film. The maximum CT absorption $\left(\lambda_{\max }\right)$ of PTOBDTTQ2 as a thin film was about $696 \mathrm{~nm}$, i.e. bathochromically shifted about $59 \mathrm{~nm}$ from that of

Table 1 Molecular weight and thermal data of the polymers

\begin{tabular}{lllll}
\hline Polymer & ${M_{\mathrm{w}}}^{a}(\mathrm{kDa})$ & ${M_{\mathrm{n}}}^{a}(\mathrm{kDa})$ & PDI $^{a}$ & $T_{\mathrm{d}}\left({ }^{\circ} \mathrm{C}\right)$ \\
\hline PTOBDTTQ1 & 21.6 & 20 & 1.08 & 356 \\
PTOBDTTQ2 & 21.8 & 20 & 1.09 & 379
\end{tabular}

${ }^{a}$ The $M_{\mathrm{w}}, M_{\mathrm{n}}$ and PDI of the polymers were estimated by GPC using polystyrene as the standard and THF as the eluent. 


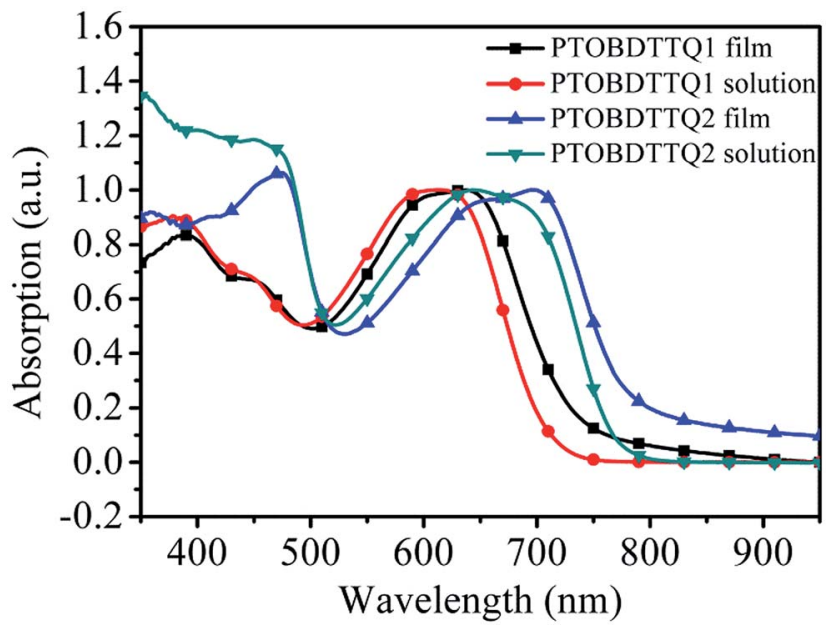

Fig. 1 UV-visible absorption spectra of the polymers in chloroform solution and as thin films.

PTOBDTTQ1, indicating the stronger electron-withdrawing ability of TQ2 compared with TQ1. In addition, PTOBDTTQ2 showed more structural absorption than PTOBDTTQ1 in the thin film form. This is because the higher planarity of TQ2 compared with TQ1 led to strong aggregation after spin-coating. The strong absorption around 350-500 $\mathrm{nm}$ of both polymers are attributed to the $\pi-\pi^{*}$ transition of the conjugated backbone, which may help to absorb more sunlight as a result of the extended $\pi-\pi$ conjugation of TOBDT. The absorption onsets of PTOBDTTQ1 and PTOBDTTQ2 in the film form are 739 and 778 $\mathrm{nm}$, corresponding, respectively, to optical band gaps $\left(E_{\mathrm{g}}^{\mathrm{opt}}\right)$ of 1.68 and $1.59 \mathrm{eV}$. The $E_{\mathrm{g}}^{\mathrm{opt}}$ of PTOBDTTQ2 is lower than reported previously. ${ }^{33,35,36,38}$ These phenomena indicate that the more planar TQ2 unit not only effectively broadens the absorption spectra, but also exhibits good $\pi-\pi$ stacking in the solid state, consistent with the design of the polymer.

\section{Electrochemical properties}

The oxidation potentials of the polymers were determined electrochemically by cyclic voltammetry $(\mathrm{CV})$ with the polymer coated on glassy carbon electrodes (Fig. 2); the electrochemical data are summarized in Table 2. The HOMO energy levels of the polymers were calculated using the equation: HOMO = $-\left[E_{\mathrm{ox}}-E_{1 / 2}^{\text {(ferrocene })}+4.8\right] \mathrm{eV}$, where $E_{\mathrm{ox}}$ is the onset oxidation potential. Thus the HOMO energy levels of PTOBDTTQ1 and PTOBDTTQ2 were calculated to be -5.33 and $-5.42 \mathrm{eV}$, respectively. It is widely acknowledged that the $V_{\mathrm{oc}}$ of PSCs is directly proportional to the difference between the HOMO energy level of the polymer donor and the lowest unoccupied molecular orbital (LUMO) energy level of the PCBM electron acceptor. Therefore it is not difficult to infer that PTOBDTTQ2 will have a higher $V_{\text {oc }}$ because of its deeper lying HOMO. In addition, the rotational angles caused by the 2-ethylhexyl side chain in TQ2 do not seem to affect the $V_{\text {oc }}$ and may even facilitate the performance of the device based on the HOMO energy level. The LUMO energy levels of the two polymers were calculated from the HOMO energy levels and $E_{\mathrm{g}}^{\mathrm{opt}}$ by the equation:
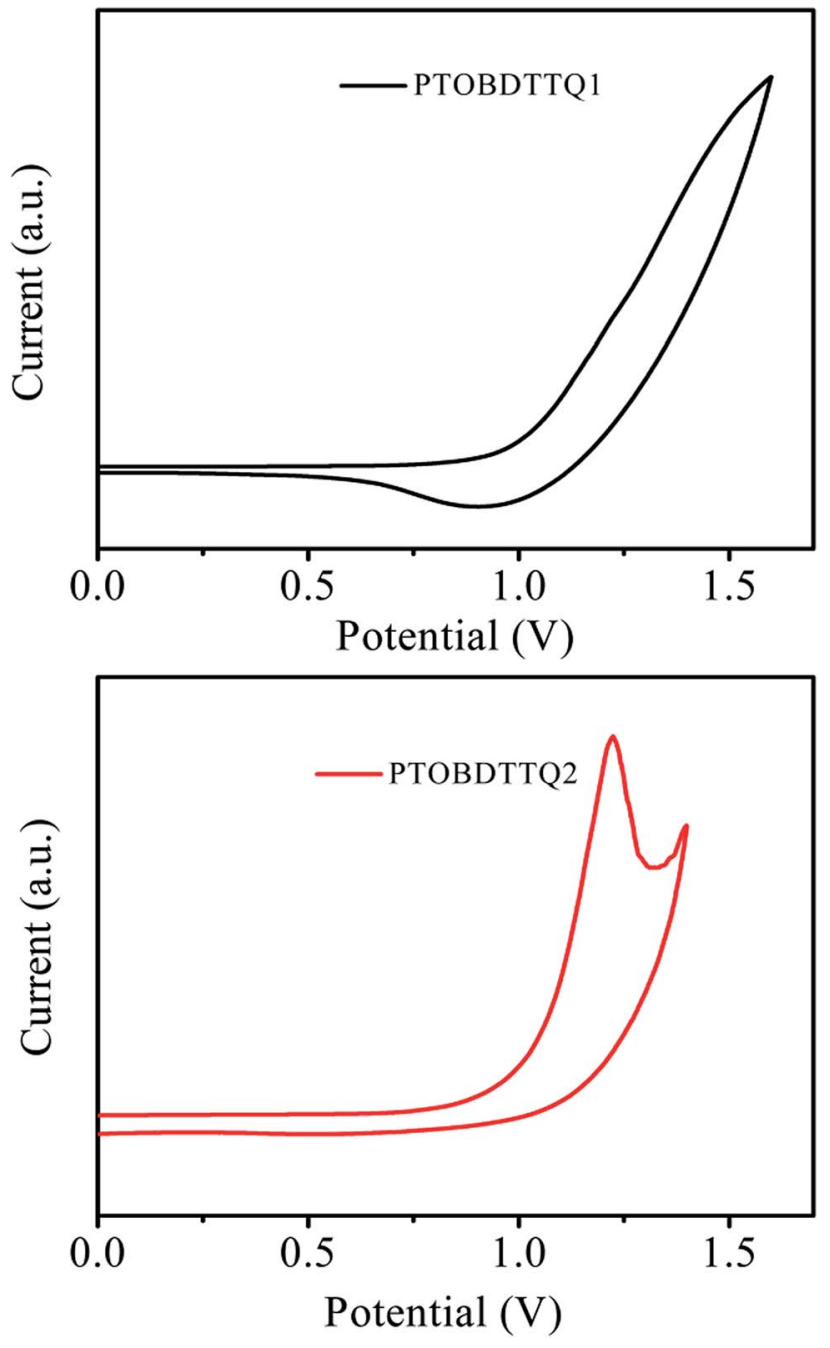

Fig. 2 Cyclic voltammetry curves of the polymer films.

$$
\mathrm{LUMO}=\mathrm{HOMO}+E_{\mathrm{g}}^{\mathrm{opt}}
$$

The high LUMO energy levels of the two polymers ensure a sufficient driving force for CT from the polymer to the PCBM. Moreover, the LUMO energy level of PTOBDTTQ2, which has a more planar quinoxaline unit, is lower than that of PTOBDTTQ1. This is consistent with a previous report ${ }^{36}$ which suggested that the LUMO delocalization of the TQ1-based polymer is mainly limited to the quinoxaline unit while it is extended onto the fused ring system as a result of the enhanced planarity of the TQ2-based polymer.

\section{Photovoltaic properties}

Solar cells were fabricated by blending PTOBDTTQ1 or PTOBDTTQ2 with $\mathrm{PC}_{71} \mathrm{BM}$. The photoactive layer was sandwiched between transparent ITO/PEDOT:PSS and reflective $\mathrm{Ca} /$ $\mathrm{Al}$ back electrodes with a structure of ITO/PEDOT:PSS/ PTOBDTTQ1 or PTOBDTTQ2:PC ${ }_{71} \operatorname{BM}(1: 2 \mathrm{w} / \mathrm{w}) / \mathrm{Ca} / \mathrm{Al}$. The active layers of the devices were spin-coated from $o$-dichlorobenzene solutions of the polymer and $\mathrm{PC}_{71} \mathrm{BM}$ at a concentration of $30 \mathrm{mg} \mathrm{mL}{ }^{-1} \cdot \mathrm{PC}_{71} \mathrm{BM}$ was selected as the electron 
Table 2 Optical and electrochemical properties of the polymers

\begin{tabular}{llllll}
\hline Polymer & $\begin{array}{l}\lambda_{\max }, \text { film } \\
(\mathrm{nm})\end{array}$ & $\begin{array}{l}\lambda_{\text {onset }}, \text { film } \\
(\mathrm{nm})\end{array}$ & $\begin{array}{l}E_{\mathrm{g}}^{\text {opt }} \\
(\mathrm{eV})\end{array}$ & $\begin{array}{l}\text { HOMO } \\
(\mathrm{eV})\end{array}$ & $\begin{array}{l}\text { LUMO } \\
(\mathrm{eV})\end{array}$ \\
\hline PTOBDTTQ1 & 388,637 & 739 & 1.68 & -5.33 & -3.65 \\
PTOBDTTQ2 & 473,696 & 778 & 1.59 & -5.42 & -3.83 \\
\hline
\end{tabular}

acceptor because it has similar electronic properties to $\mathrm{PC}_{61} \mathrm{BM}$, but a considerably higher absorption coefficient in the visible region. As the ratio of polymer: $\mathrm{PC}_{71} \mathrm{BM}$ is an important parameter, the weight ratio between the polymer and $\mathrm{PC}_{71} \mathrm{BM}$ was optimized to $1: 2$. Table 3 lists the photovoltaic properties of the devices.

The devices were measured under the simulated AM 1.5G illumination condition $\left(100 \mathrm{~mW} \mathrm{~cm}^{-2}\right)$ after annealing at 110 ${ }^{\circ} \mathrm{C}$ for $10 \mathrm{~min}$. Fig. 3a shows the current-voltage ( $J-V$ curves) of the PSCs. The PTOBDTTQ1 device has a $V_{\text {oc }}$ of $0.76 \mathrm{~V}$, a $J_{\text {sc }}$ of $7.49 \mathrm{~mA} \mathrm{~cm}^{-2}$ and an FF of $47 \%$, resulting in a PCE of $2.66 \%$. The PTOBDTTQ2 device shows an increased PCE of $4.24 \%$ with a $V_{\text {oc }}$ of $0.83 \mathrm{~V}$, a $J_{\text {sc }}$ of $9.40 \mathrm{~mA} \mathrm{~cm} \mathrm{~cm}^{-2}$ and an $\mathrm{FF}$ of $54 \%$. The results are in close agreement with previous assumptions about the PSCs. The slightly increased $V_{\text {oc }}$ of PTOBDTTQ2 is consistent with its deeper HOMO level compared with that of PTOBDTTQ1. This is further proof that the 2-ethylhexyl side chain in TQ2 facilitates the performance of the device. The increased $J_{\text {sc }}$ value may contribute to the significantly improved PCE of PTOBDTTQ2. With respect to the $J_{\mathrm{sc}}$ value, the difference can be inferred to be due to two reasons: first, PTOBDTTQ2 has a broader absorption spectrum than PTOBDTTQ1, as previously shown in Fig. 1; and, second, PTOBDTTQ2 may have a higher charge mobility than PTOBDTTQ1 due to the enhanced $\pi-\pi$ stacking in the more planar structure of TQ2.

To confirm this speculation, the hole mobility was measured by the space charge limited current (SCLC) $J-V$ curves as obtained in the dark using hole-only devices (ITO/PEDOT:PSS/ polymer: $\left.\mathrm{PC}_{71} \mathrm{BM} / \mathrm{Au}\right)$. The SCLC behavior in the trap-free region can be characterized using the Mott-Gurney square law. ${ }^{37}$ The hole mobility of PTOBDTTQ2 was calculated to be $5.42 \times 10^{-5}$ $\mathrm{cm}^{2} \mathrm{~V}^{-1} \mathrm{~s}^{-1}$, higher than the $2.44 \times 10^{-5} \mathrm{~cm}^{2} \mathrm{~V}^{-1} \mathrm{~s}^{-1}$ of PTOBDTTQ1 (Fig. 4). The higher hole mobility of PTOBDTTQ2 is expected to contribute in part to the higher $J_{\mathrm{sc}}$ and $\mathrm{FF}$ values observed in the solar cell devices. ${ }^{39}$

To confirm the PCE, the EQE of the devices was measured under illumination with monochromatic light. As shown in Fig. 3b, the PTOBDTTQ1 device shows a photo response between 300 and $750 \mathrm{~nm}$, although the photo response of the PTOBDTTQ2 device extends to around $800 \mathrm{~nm}$. The device

Table 3 Photovoltaic properties of the devices under the simulated AM 1.5G illumination condition

\begin{tabular}{lllll}
\hline $\begin{array}{l}\text { Polymer:PC } \\
(1: 2 \mathrm{BM} / \mathrm{w})\end{array}$ & $\begin{array}{l}V_{\mathrm{oc}} \\
(\mathrm{V})\end{array}$ & $\begin{array}{l}J_{\mathrm{sc}} \\
\left.(\mathrm{mA} \mathrm{cm})^{-2}\right)\end{array}$ & $\begin{array}{l}\mathrm{FF} \\
(\%)\end{array}$ & $\begin{array}{l}\text { PCE } \\
(\%)\end{array}$ \\
\hline PTOBDTTQ1 & 0.76 & 7.49 & 47 & 2.66 \\
PTOBDTTQ2 & 0.83 & 9.40 & 54 & 4.24
\end{tabular}
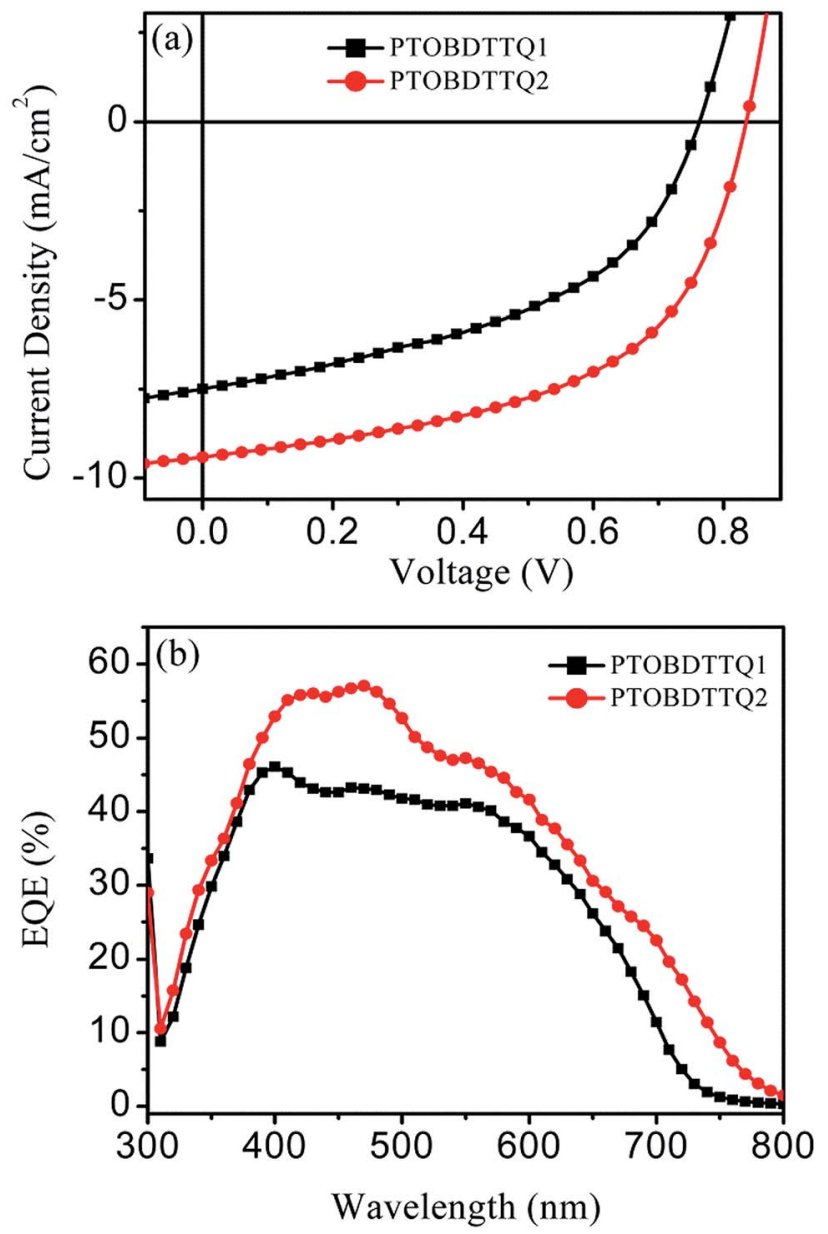

Fig. 3 (a) $J-V$ curves of PTOBDTTQ1:PC ${ }_{71} B M$ and PTOBDTTQ2:PC ${ }_{71} B M(1: 2 \mathrm{w} / \mathrm{w})$. (b) External quantum efficiency (EQE) spectra of the PSCs.

based on PTOBDTTQ2 shows higher EQE values, along with broader absorption spectra. This result again indicates that the more planar TQ2 is helpful in improving the $J_{\mathrm{sc}}$ performance of the device. Both the current density $\left(J_{\mathrm{sc}}\right)$ values, calculated by the integration of the EQE of the devices, are close to the $J_{\mathrm{sc}}$ values obtained from the $J-V$ curves.

Atomic force microscopy (AFM) was used to investigate the morphology of the polymer and $\mathrm{PC}_{71} \mathrm{BM}$ blend films. Fig. 5 shows AFM images of PTOBDTTQ1:PC ${ }_{71} \mathrm{BM}(1: 2 \mathrm{w} / \mathrm{w})$ and PTOBDTTQ2:PC ${ }_{71} \mathrm{BM}(1: 2 \mathrm{w} / \mathrm{w})$ films after annealing at $110{ }^{\circ} \mathrm{C}$ for $10 \mathrm{~min}$. Both films show a close surface roughness of 1.65 and $1.93 \mathrm{~nm}$, respectively, and a similar degree of phase separation, which relates to the charge separation. A $1 \times 1 \mu \mathrm{m} \mathrm{AFM}$ (Fig. S1 $\dagger$ ) image was also obtained that shows a similar height image and RMS value to the $5 \times 5 \mu \mathrm{m}$ AFM images.

\section{Experimental section}

\section{Reagents and measurements}

Common solvents were purchased as analytical-reagent grade and used as received. Deuterated chloroform $\left(\mathrm{CDCl}_{3}\right)$ and $o$ dichlorobenzene (o-DCB) were purchased from Sigma-Aldrich. THF and toluene were dried over sodium-benzophenone under 


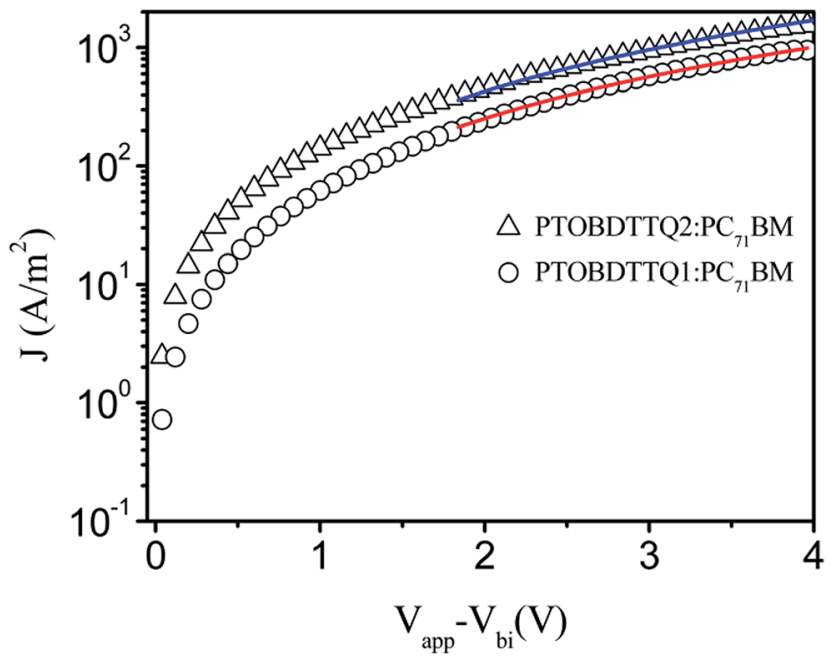

Fig. 4 Dark J-V characteristics of polymer: $\mathrm{PC}_{71} \mathrm{BM}$ with hole-only devices. The solid lines are the best linear fit of the data points.
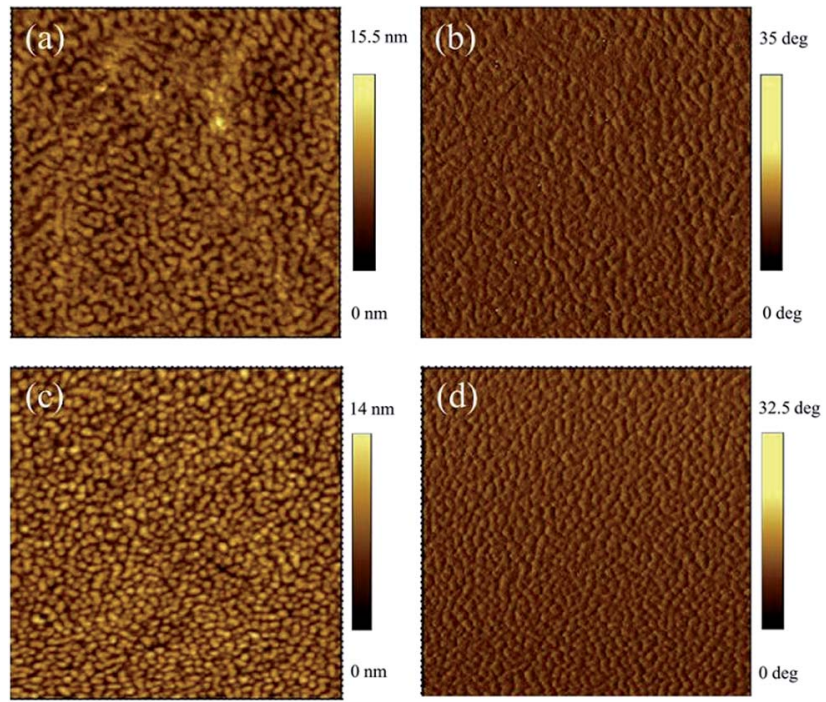

Fig. 5 Atomic force microscopy images: (a and c) PTOBDTTQ1:PC ${ }_{71} B M$ and PTOBDTTQ2:PC ${ }_{71} B M$ height image respectively; ( $b$ and $d$ ) PTOBDTTQ1 and PTOBDTTQ2 phase image, respectively. All images are $5 \times 5 \mu \mathrm{m}$.

nitrogen and were freshly distilled before use. Bis(triphenylphosphine)palladium(II)chloride $\left[\mathrm{Pd}\left(\mathrm{PPh}_{3}\right)_{2} \mathrm{Cl}_{2}\right]$, tris(dibenzylideneacetone)dipalladium $\quad\left[\mathrm{Pd}_{2}(\mathrm{dba})_{3}\right]$, tri(o-tolyl)phosphine $\left[\mathrm{P}(o \text {-tol })_{3}\right]$ and tetrabutylammoniumhexafluorophospate $\left(\mathrm{Bu}_{4} \mathrm{NPF}_{6}\right)$ were from Aladdin or Sigma-Aldrich. Nuclear magnetic resonance (NMR) spectra were measured in $\mathrm{CDCl}_{3}$ on a Bruker AVANCE $600 \mathrm{MHz}$ Fourier transform NMR spectrometer; the chemical shifts were quoted relative to the internal standard tetramethylsilane. UV-visible absorption spectra were measured using a Hitachi U-4100 UV-visible-NIR scanning spectrophotometer. CV measurements were made on a CHI660D electrochemical work station. The CV was carried out in a $0.1 \mathrm{M}$ anhydrous acetonitrile solution of $\mathrm{Bu}_{4} \mathrm{NPF}_{6}$ with a platinum wire counter electrode and saturated calomel reference electrode; the working electrode was a glassy carbon electrode coated with the two polymer films. The molecular weights of the polymers were measured by GPC using an ELEOS system with polystyrene as the standard (room temperature) and THF as the eluent. Thermogravimetric analysis measurements were made using an SDT Q600 V20.9 Build 20 instrument at a heating rate of $10^{\circ} \mathrm{C} \mathrm{min}^{-1}$. AFM images were acquired with an Agilent-5400 scanning probe microscope with a Nano drive controller in the tapping mode with MikroMasch NSC-15 AFM tips with resonant frequencies of about $300 \mathrm{kHz}$.

Both of the PSCs were fabricated with the same conventional device structure (ITO/PEDOT:PSS/PTOBDTTQ1 or PTOBDTTQ2:PC $\left.{ }_{71} \mathrm{BM}(1: 2 \quad \mathrm{w} / \mathrm{w}) / \mathrm{Ca} / \mathrm{Al}\right)$. ITO-coated glass substrates were sequentially cleaned ultrasonically in detergent, water, acetone and isopropanol, followed by treatment in an oxygen plasma (Plasma Preen II-862 Cleaner). A thin layer ( $\sim 40 \mathrm{~nm}$ ) of PEDOT:PSS (Heraeus Clevios TM P AI 4083) was spin-coated onto the pre-cleaned ITO-coated glass substrates and annealed in an oven at $150{ }^{\circ} \mathrm{C}$ for $20 \mathrm{~min}$. The substrates were then transferred into an argon-filled glove-box. PTOBDTTQ1 or PTOBDTTQ2 and $\mathrm{PC}_{71} \mathrm{BM}$ (American Dye Source) were dissolved in $o$-DCB without DIO solvent. The solution was then stirred overnight at room temperature. The solution of polymer: $\mathrm{PC}_{71} \mathrm{BM}$ was then spin-coated to form the active layer $(\sim 100 \mathrm{~nm})$ on the PEDOT:PSS modified ITO-coated glass. The devices were completed after the deposition of $\mathrm{Ca}$ $(10 \mathrm{~nm}) / \mathrm{Al}(100 \mathrm{~nm})$ as the cathode through a shadow mask under a high vacuum $\left(\sim 10^{-4} \mathrm{~Pa}\right)$. The thickness of the active layer was controlled by changing the spin speed during the spincoating process and was estimated using a Veeco Dektak150 surface profiler in our laboratory. The effective area of the device was measured to be $0.1 \mathrm{~cm}^{2}$. The current density-voltage $(J-V)$ characteristics of the PSCs were recorded using a Keithley 2420 source measurement unit under AM 1.5G illumination $(100 \mathrm{~mW}$ $\mathrm{cm}^{-2}$, Newport solar simulator). The light intensity was calibrated with a standard silicon solar cell. The EQE of the solar cells was analyzed using a certified Newport incident photon conversion efficiency (IPCE) measurement system.

\section{Synthesis}

The monomers (4,8-bis(5-(3,4,5-tris(octyloxy)phenyl)thiophen2-yl)benzo[1,2- $\left.b: 4,5-b^{\prime}\right]$ dithiophene-2,6-diyl)bis(trimethylstannane) (TOBDTSn), ${ }^{37}$ tributyl(thiophen-2-yl)stannane, ${ }^{40} 5,8$ dibromo-2,3-diphenylquinoxaline (1), ${ }^{41}$ tributyl(4-(2-ethylhexyl)thiophen-2-yl)stannane ${ }^{42}$ and 10,13-dibromodibenzo[a,c]phenazine $(2)^{41}$ were synthesized according to reference methods. ${ }^{38,43-45}$

Synthesis of 2,3-diphenyl-5,8-di(thiophen-2-yl)quinoxaline (TQ1). $\mathrm{Pd}\left(\mathrm{PPh}_{3}\right)_{2} \mathrm{Cl}_{2}(0.05 \mathrm{~g}, 0.075 \mathrm{mmol})$ was added to a solution of tributyl(thiophen-2-yl)stannane $(1.68 \mathrm{~g}, 4.5 \mathrm{mmol})$ and 5,8-dibromo-2,3-diphenylquinoxaline (1) (0.66 g, $1.5 \mathrm{mmol})$ in dry toluene $(20 \mathrm{~mL})$ under an argon atmosphere. The mixture was then refluxed overnight. After cooling to room temperature the solvent was removed under reduced pressure and the residue was purified by silica gel column chromatography 
(eluent petroleum ether- $\mathrm{CH}_{2} \mathrm{Cl}_{2}, 3: 1 \mathrm{v} / \mathrm{v}$ ) to yield an yellow solid (yield 85\%, $0.57 \mathrm{~g}$ ). ${ }^{1} \mathrm{H}-\mathrm{NMR}\left(600 \mathrm{MHz}, \mathrm{CDCl}_{3}\right): \delta$ (ppm) $8.15(\mathrm{~s}, 2 \mathrm{H}), 7.89-7.86(\mathrm{~m}, 2 \mathrm{H}), 7.74(\mathrm{dd}, J=7.6,1.7 \mathrm{~Hz}, 4 \mathrm{H})$, $7.52(\mathrm{dd}, J=5.0,0.6 \mathrm{~Hz}, 2 \mathrm{H}), 7.39(\mathrm{t}, J=6.2 \mathrm{~Hz}, 6 \mathrm{H}), 7.18(\mathrm{dd}, J=$ $5.0,3.8 \mathrm{~Hz}, 2 \mathrm{H})$.

Synthesis of 10,13-bis(4-(2-ethylhexyl)thiophen-2-yl)dibenzo $[a, c]$ phenazine (TQ2). $\mathrm{Pd}\left(\mathrm{PPh}_{3}\right)_{2} \mathrm{Cl}_{2}(0.05 \mathrm{~g}, 0.075 \mathrm{mmol})$ was added to a solution of tributyl(4-(2-ethylhexyl)thiophen-2-yl) stannane $(2.18 \mathrm{~g}, 4.5 \mathrm{mmol})$ and 10,13-dibromodibenzo[a,c] phenazine (2) $(0.66 \mathrm{~g}, 1.5 \mathrm{mmol})$ in dry toluene $(20 \mathrm{~mL})$ under an argon atmosphere. The mixture was refluxed overnight. After cooling to room temperature, the solvent was removed under reduced pressure and the residue was purified by silica gel column chromatography (eluent petroleum ether- $\mathrm{CH}_{2} \mathrm{Cl}_{2} .4: 1$ $\mathrm{v} / \mathrm{v}$ ) to yield a red solid (yield $80 \%, 0.81 \mathrm{~g}) .{ }^{1} \mathrm{H}-\mathrm{NMR}(600 \mathrm{MHz}$, $\left.\mathrm{CDCl}_{3}\right): \delta(\mathrm{ppm}) 9.50(\mathrm{dd}, J=7.6,1.6 \mathrm{~Hz}, 2 \mathrm{H}), 8.50(\mathrm{~d}, J=7.4 \mathrm{~Hz}$, $2 \mathrm{H}), 8.15(\mathrm{~s}, 2 \mathrm{H}), 7.77-7.70(\mathrm{~m}, 6 \mathrm{H}), 7.20(\mathrm{~s}, 2 \mathrm{H}), 2.68(\mathrm{dd}, J=$ 6.8, 3.3 Hz, 4H), 1.73 (s, 2H), 1.44-1.30 (m, 16H), 0.99-0.91 (m, $12 \mathrm{H})$.

Synthesis of 5,8-bis(5-bromothiophen-2-yl)-2,3-diphenylquinoxaline (DBrTQ1). NBS (0.39 g, $2.2 \mathrm{mmol})$ was added slowly in the dark to a solution of compound TQ1 $(0.44 \mathrm{~g}, 1 \mathrm{mmol})$ in $\mathrm{CHCl}_{3}$ and acetic acid (12 $\mathrm{mL}, \mathrm{CHCl}_{3}$-acetic acid, $\left.5: 1 \mathrm{v} / \mathrm{v}\right)$. The mixture was stirred for $1 \mathrm{~h}$ and then poured into water, extracted with $\mathrm{CH}_{2} \mathrm{Cl}_{2}$ and washed with $\mathrm{NaHCO}_{3}$ saturated solution. The organic phase was dried over anhydrous $\mathrm{Na}_{2} \mathrm{SO}_{4}$. After removing the solvent under reduced pressure, the residue was purified by silica gel column chromatography (eluent petroleum ether- $\mathrm{CH}_{2} \mathrm{Cl}_{2}, 4: 1 \mathrm{v} / \mathrm{v}$ ) and then recrystallized from isopropanol to yield a deep orange fluffy solid (yield 80\%, 0.49 g). ${ }^{1} \mathrm{H}-\mathrm{NMR}\left(600 \mathrm{MHz}, \mathrm{CDCl}_{3}\right): \delta(\mathrm{ppm}) 8.04(\mathrm{~s}, 2 \mathrm{H}), 7.69(\mathrm{~d}, J=$ $6.8 \mathrm{~Hz}, 4 \mathrm{H}), 7.55(\mathrm{~d}, J=4.0 \mathrm{~Hz}, 2 \mathrm{H}), 7.44-7.38(\mathrm{~m}, 6 \mathrm{H}), 7.11(\mathrm{~d}, J$ $=4.0 \mathrm{~Hz}, 2 \mathrm{H}) .{ }^{13} \mathrm{C}-\mathrm{NMR}\left(150 \mathrm{MHz}, \mathrm{CDCl}_{3}\right): \delta(\mathrm{ppm})$ 152.23, 139.60, 138.21, 136.70, 130.66, 130.50, 129.24, 129.17, 128.33, 125.80, 125.65, 117.18 .

Synthesis of 10,13-bis(5-bromo-4-(2-ethylhexyl)thiophen-2yl)dibenzo[ $\boldsymbol{a}, \boldsymbol{c}]$ phenazine (DBrTQ2). NBS (0.39 $\mathrm{g}, 2.2 \mathrm{mmol})$ was added slowly in the dark to a solution of compound TQ2 $(0.67 \mathrm{~g}$, $1 \mathrm{mmol})$ in $\mathrm{CHCl}_{3}$ and acetic acid $\left(12 \mathrm{~mL}, \mathrm{CHCl}_{3}\right.$-acetic acid, $5: 1 \mathrm{v} / \mathrm{v})$. The mixture was stirred for $1 \mathrm{~h}$ and then poured into water, extracted with $\mathrm{CH}_{2} \mathrm{Cl}_{2}$ and washed with $\mathrm{NaHCO}_{3}$ saturated solution. The organic phase was dried over anhydrous $\mathrm{Na}_{2} \mathrm{SO}_{4}$. After removing the solvent under reduced pressure, the residue was purified by silica gel column chromatography (eluent petroleum ether- $\mathrm{CH}_{2} \mathrm{Cl}_{2}, 5: 1 \mathrm{v} / \mathrm{v}$ ) then washed in hot methanol to yield a deep purple solid (yield $80 \%, 0.66 \mathrm{~g}$ ). ${ }^{1} \mathrm{H}$ NMR (600 MHz, $\mathrm{CDCl}_{3}$ ): $\delta(\mathrm{ppm}) 9.21$ (dd, $J=7.7,0.8 \mathrm{~Hz}, 2 \mathrm{H}$ ), 8.37 (d, $J=7.8 \mathrm{~Hz}, 2 \mathrm{H}), 7.86$ (s, 2H), 7.67 (ddd, $J=20.6,14.0,6.8$ $\mathrm{Hz}, 4 \mathrm{H}), 7.38(\mathrm{~s}, 2 \mathrm{H}), 2.58(\mathrm{dd}, J=7.2,2.5 \mathrm{~Hz}, 4 \mathrm{H}), 1.78-1.70(\mathrm{~m}$, $2 \mathrm{H}), 1.48-1.31(\mathrm{~m}, 17 \mathrm{H}), 0.97(\mathrm{dt}, J=14.0,7.3 \mathrm{~Hz}, 12 \mathrm{H}) .{ }^{13} \mathrm{C}-$ NMR (150 MHz, $\mathrm{CDCl}_{3}$ ): $\delta$ (ppm) 141.60, 140.32, 137.70, 137.41, 132.19, 130.32, 130.29, 130.02, 127.94, 127.75, 126.78, 125.29, $122.65,114.62,40.18,33.85$, 32.62, 28.92, 25.76, 23.18, 14.23, 10.96 .

Synthesis of polymer PTOBDTTQ1. TOBDTSn (320.3 mg, 0.2 mmol), DBrTQ1 (121.3 mg, $0.2 \mathrm{mmol}), \mathrm{Pd}_{2}(\mathrm{dba})_{3}(1.8 \mathrm{mg}, 0.002$ $\mathrm{mmol})$ and $\mathrm{P}(o \text {-tol })_{3}(3.6 \mathrm{mg}, 0.012 \mathrm{mmol})$ were dissolved into 6
$\mathrm{mL}$ of toluene in a flask protected by argon. The mixture was then heated at $110{ }^{\circ} \mathrm{C}$ for $24 \mathrm{~h}$. After cooling to room temperature, the mixture was poured into methanol. The precipitated solid was collected and purified by Soxhlet extraction and silica gel column chromatography with chloroform as the eluent. After drying overnight under vacuum, the target polymer was obtained as a dark solid, yield $80 \%, 276 \mathrm{mg} \cdot M_{\mathrm{n}}=20 \mathrm{kDa}, \mathrm{PDI}=$ 1.08. ${ }^{1} \mathrm{H}-\mathrm{NMR}\left(600 \mathrm{MHz}, \mathrm{CDCl}_{3}\right.$ ): $\delta$ (ppm) 8.65-5.84 (br, 26H), 4.51-3.25 (m, 12H), 2.00-0.18 (m, 90H).

Synthesis of polymer PTOBDTTQ2. PTOBDTTQ2 was synthesized by the same procedure as PTOBDTTQ1. TOBDTSn (320.3 mg, $0.2 \mathrm{mmol}$ ), DBrTQ2 (168.6 mg, $0.2 \mathrm{mmol}$ ), $\mathrm{Pd}_{2}(\mathrm{dba})_{3}$ $(1.8 \mathrm{mg}, 0.002 \mathrm{mmol})$ and $\mathrm{P}(o \text {-tol })_{3}(3.6 \mathrm{mg}, 0.012 \mathrm{mmol})$ were used. Yield 75\%, $292 \mathrm{mg} . M_{\mathrm{n}}=20 \mathrm{kDa}, \mathrm{PDI}=1.09 .{ }^{1} \mathrm{H}-\mathrm{NMR}$ (600 MHz, $\left.\mathrm{CDCl}_{3}\right): \delta(\mathrm{ppm})$ 9.07-5.42 (br, 22H), 4.61-3.41 (m, $16 \mathrm{H}), 2.28-0.21(\mathrm{~m}, 120 \mathrm{H})$.

\section{Conclusions}

The new polymer PTOBDTTQ2, based on TQ2 and the 2D-BDT unit, was designed, synthesized and characterized. Compared with TQ1, which has two separated phenyl rings, TQ2 has a more planar structure because the two phenyl rings are connected by a single bond; this facilitates $\pi-\pi$ stacking and charge transport. With the help of the highly soluble TOBDT with six alkoxylated substituents, the polymer could be processed in solution. The PSCs fabricated from the blend of the polymer and $\mathrm{PC}_{71} \mathrm{BM}$ have PCEs of 2.66 and $4.24 \%$, respectively. These results show that the quinoxaline derivative TQ2 is a promising acceptor unit and further research and improvement of this derivative are indicated.

\section{Acknowledgements}

The authors are deeply grateful to the National Natural Science Foundation of China (Projects 21274134, 51173199, 51303197 and 61107090), New Century Excellent Talents in University (NCET-11-0473) and the Qingdao Municipal Science and Technology Program (13-1-4-200-jch) for financial support.

\section{Notes and references}

1 G. Yu, J. Gao, J. Hummelen, F. Wudl and A. J. Heeger, Science, 1995, 270, 1789-1790.

2 S. Günes, H. Neugebauer and N. S. Sariciftci, Chem. Rev., 2007, 107, 1324-1338.

3 A. Gadisa, W. Mammo, L. M. Andersson, S. Admassie, F. Zhang, M. R. Andersson and O. Inganäs, Adv. Funct. Mater., 2007, 17, 3836-3842.

4 Y. J. Cheng, S. H. Yang and C. S. Hsu, Chem. Rev., 2009, 109, 5868-5923.

5 X. Guo, C. Cui, M. Zhang, L. Huo, Y. Huang, J. Hou and Y. Li, Energy Environ. Sci., 2012, 5, 7943-7949.

6 C. Duan, K. Zhang, X. Guan, C. Zhong, H. Xie, F. Huang, J. Chen, J. Peng and Y. Cao, Chem. Sci., 2013, 4, 1298-1307.

7 B. C. Thompson and J. M. Fréchet, Angew. Chem., Int. Ed., 2008, 47, 58-77. 
8 Y. Zhang, S. K. Hau, H. L. Yip, Y. Sun, O. Acton and A. K. Y. Jen, Chem. Mater., 2010, 22, 2696-2698.

9 M. D. Irwin, D. B. Buchholz, A. W. Hains, R. P. Chang and T. J. Marks, Proc. Natl. Acad. Sci. U. S. A., 2008, 105, 27832787.

10 C. Y. Chang, C. E. Wu, S. Y. Chen, C. Cui, Y. J. Cheng, C. S. Hsu, Y. L. Wang and Y. Li, Angew. Chem., Int. Ed., 2011, 50, 9386-9390.

11 Y. Sun, C. Cui, H. Wang and Y. Li, Adv. Energy Mater., 2011, 1, 1058-1061.

12 S. H. Liao, Y. L. Li, T. H. Jen, Y.-S. Cheng and S. A. Chen, J. Am. Chem. Soc., 2012, 134, 14271-14274.

13 Z. He, C. Zhong, X. Huang, W. Y. Wong, H. Wu, L. Chen, S. Su and Y. Cao, Adv. Mater., 2011, 23, 4636-4643.

14 J. S. Moon, J. Jo and A. J. Heeger, Adv. Energy Mater., 2012, 2, 304-308.

15 L. Ye, S. Zhang, L. Huo, M. Zhang and J. Hou, Acc. Chem. Res., 2014, 47, 1595-1603.

16 Q. Liu, X. Bao, S. Wen, Z. Du, L. Han, D. Zhu, Y. Chen, M. Sun and R. Yang, Polym. Chem., 2014, 5, 2076-2082.

17 L. Huo, S. Zhang, X. Guo, F. Xu, Y. Li and J. Hou, Angew. Chem., Int. Ed., 2011, 50, 9697-9702.

18 L. Huo and J. Hou, Polym. Chem., 2011, 2, 2453-2461.

19 L. Huo, X. Guo, S. Zhang, Y. Li and J. Hou, Macromolecules, 2011, 44, 4035-4037.

20 L. Huo, L. Ye, Y. Wu, Z. Li, X. Guo, M. Zhang, S. Zhang and J. Hou, Macromolecules, 2012, 45, 6923-6929.

21 X. Li, W. C. Choy, L. Huo, F. Xie, W. E. Sha, B. Ding, X. Guo, Y. Li, J. Hou and J. You, Adv. Mater., 2012, 24, 3046-3052.

22 S. Liu, K. Zhang, J. Lu, J. Zhang, H. L. Yip, F. Huang and Y. Cao, J. Am. Chem. Soc., 2013, 135, 15326-15329.

23 S. H. Liao, H. J. Jhuo, Y. S. Cheng and S. A. Chen, Adv. Mater., 2013, 25, 4766-4771.

24 Z. A. Tan, L. Li, F. Wang, Q. Xu, S. Li, G. Sun, X. Tu, X. Hou, J. Hou and Y. Li, Adv. Energy Mater., 2014, 4, 1-7.

25 C. M. Cabanetos, A. El Labban, J. A. Bartelt, J. D. Douglas, W. R. Mateker, J. M. Fréchet, M. D. McGehee and P. M. Beaujuge, J. Am. Chem. Soc., 2013, 135, 4656-4659.

26 M. Svensson, F. Zhang, S. C. Veenstra, W. J. Verhees, J. C. Hummelen, J. M. Kroon, O. Inganäs and M. R. Andersson, Adv. Mater., 2003, 15, 988-991.

27 C. Piliego, T. W. Holcombe, J. D. Douglas, C. H. Woo, P. M. Beaujuge and J. M. Fréchet, J. Am. Chem. Soc., 2010, 132, 7595-7597.
28 M. M. Wienk, M. Turbiez, J. Gilot and R. A. Janssen, Adv. Mater., 2008, 20, 2556-2560.

29 H. Y. Chen, J. H. Hou, S. Q. Zhang, Y. Y. Liang, G. W. Yang, Y. Yang, L. P. Yu, Y. Wu and G. Li, Nat. Photonics, 2009, 3, 649-653.

30 A. Tsami, T. W. Bünnagel, T. Farrell, M. Scharber, S. A. Choulis, C. J. Brabec and U. Scherf, J. Mater. Chem., 2007, 17, 1353-1355.

31 J.-Y. Lee, W. S. Shin, J. R. Haw and D. K. Moon, J. Mater. Chem., 2009, 19, 4938-4945.

32 D. Kitazawa, N. Watanabe, S. Yamamoto and J. Tsukamoto, Appl. Phys. Lett., 2009, 95, 3701.

33 E. Zhou, J. Cong, K. Tajima and K. Hashimoto, Chem. Mater., 2010, 22, 4890-4895.

34 E. Wang, L. Hou, Z. Wang, S. Hellström, F. Zhang, O. Inganäs and M. R. Andersson, Adv. Mater., 2010, 22, 5240-5244.

35 P. Yang, M. Yuan, D. F. Zeigler, S. E. Watkins, J. A. Lee and C. K. Luscombe, J. Mater. Chem. C, 2014, 2, 3278-3284.

36 Y. Zhang, J. Zou, H. L. Yip, K. S. Chen, D. F. Zeigler, Y. Sun and A. K. Y. Jen, Chem. Mater., 2011, 23, 2289-2291.

37 L. Han, X. Bao, T. Hu, Z. Du, W. Chen, D. Zhu, Q. Liu, M. Sun and R. Yang, Macromol. Rapid Commun., 2014, 35, 11531157.

38 Y. Lee, Y. M. Nam and W. H. Jo, J. Mater. Chem., 2011, 21, 8583-8590.

39 H. C. Chen, Y. H. Chen, C. C. Liu, Y. C. Chien, S. W. Chou and P. T. Chou, Chem. Mater., 2012, 24, 4766-4772.

40 J. T. Pinhey and E. G. Roche, J. Chem. Soc., Perkin Trans. 1, 1988, 2415-2421.

41 M. J. Edelmann, J.-M. Raimundo, N. F. Utesch, F. Diederich, C. Boudon, J. P. Gisselbrecht and M. Gross, Helv. Chim. Acta, 2002, 85, 2195-2213.

42 Y. Zhang, K. Tajima, K. Hirota and K. Hashimoto, J. Am. Chem. Soc., 2008, 130, 7812-7813.

43 M. Sun, Q. Niu, B. Du, J. Peng, W. Yang and Y. Cao, Macromol. Chem. Phys., 2007, 208, 988-993.

44 M. Sun, L. Wang, Y. Xia, B. Du, R. Liu and Y. Cao, Acta Polym. Sin., 2007, 10, 952.

45 M. Sun, J. Yu, X. Huang, H. Xue and C. S. Lee, RSC Adv., 2013, 3, 23704-23708. 